\title{
ARTE Y CULTURA EN LA PINTURA AMAZÓNICA CONTEMPORÁNEA: "EL BÚHO” DE GUÍMER GARCÍA
}

\author{
Daniel Castillo T.
}

\section{Resumen:}

El artículo presenta una relación de dependencia entre la obra artística y la cultura del autor, señalando que es imposible comprender a profundidad una obra de arte sin tomar en cuenta la variable cultural. Por ello, solo un acercamiento al autor basado en entrevistas y en una aproximación etnográfica, nos ha permitido analizar y entender la producción del artista que no es reconocido como tal sí como parte de un grupo de artesanos étnico-amazónico. Al mismo tiempo, ideas importantes como las de Homi Bhabha tendrían que considerar la cultura y ser repensadas antes de ser aplicadas o adaptadas en asuntos particulares y ajenos, caso de la pintura indìgena. El resultado es una interpretación diferente y posmoderna de la obra "El Búho" del pintor amazónico-peruano Guímer García, la cual muestra la obra artística en términos culturales complejos y originales que podrían permitir una revaloración importante y una reconsideración al artista.

Palabras claves: Cultura, Pintura, Shipibo, Interpretación, Arte amazónico

\begin{abstract}
:
This article reveals the relation between the author's artistic work and his culture, showing it is impossible to understand a work of art without knowing it's cultural context. This is an approach to the author, based on interviews applied like ethnographic methodology, which has allowed us to analyze and comprehend the artist's production, for he is known as such only by an ethno-Amazonian artisan group. In this text, important ideas about culture are reevaluated before applied to the case of indigenous painting. The outcome is a different interpretation of the piece "El búho" by the Amazonian-Peruvian painter Guímer García. This piece shows the work of art in complex cultural terms that allow to rethink the artist's work.
\end{abstract}

Keywords: Culture, Painting, Shipibo, Interpretation, Amazonian art

\section{Autor:}

Daniel Castillo. Universidad Nacional de San Agustín de Arequipa. 


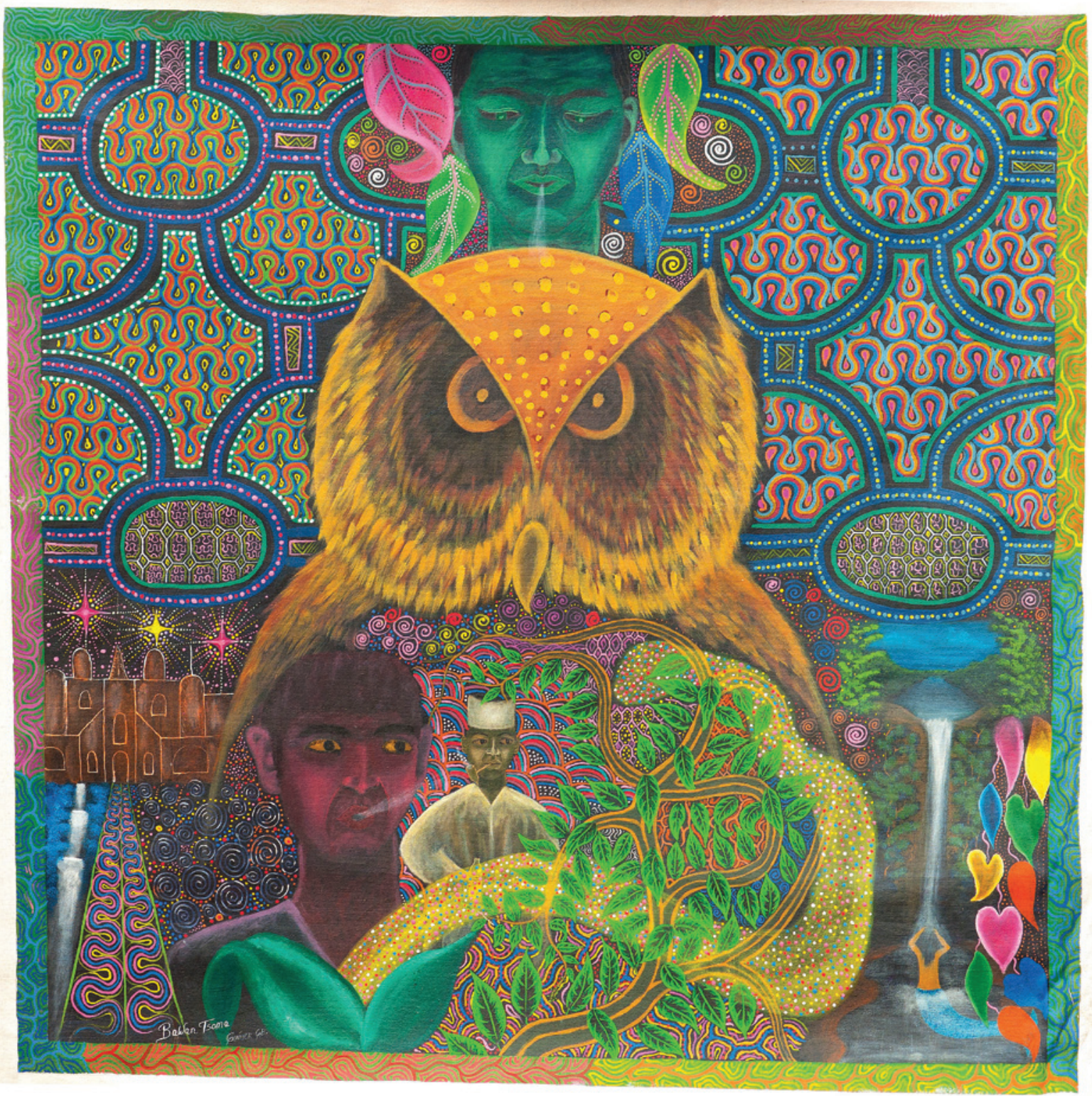

Figura 01. Fotógrafo Daniel Castillo. Pintura "El búho" de Guimer García. 2012.

\section{La obra de Guímer García y sus interpretaciones}

Esta pintura pertenece a Guímer García, un pintor shipibo que migró a Lima y se unió a la comunidad de migrantes amazónicos llamada Cantagallo. Titulada "El búho", la obra enmarca cualquier mirada en los límites de un formato plano y cuadrangular, lleno de colores y figuras que nos recuerdan la incomprensibilidad de los cuadros de Vincent Van Gogh o Toulouse Lautrec cuando fueron presentados por primera vez en Europa, y que ahora están colgados en la pared de algún museo famoso con precios que los autores nunca pudieron imaginárselos, porque no fueron valorados como debía ser en sus épocas; pero que nos hacen indagar sobre las reglas de juego para quien tiene el dominio del pincel que deja el pigmento sobre la tela. Cabe preguntarse: ¿Tiene esta obra algún valor que está pasando por desapercibido? ¿Por qué la obra de Guímer García no ha sido exhibida aún en museos o galerías de arte contemporáneo del Perú o del mundo? Las especulaciones señalan 
que una de las respuestas podría indicar que los artistas Shipibo aún no conocen todas las reglas o cánones estéticos de las bellas artes europeas, que durante siglos han seguido un patrón y que llegaron a las Américas a consecuencia de la colonización y que, a pesar de las independencias, estas artes nunca se fueron hasta el día de hoy. En el Perú, por ejemplo, el arte de la pintura tomó vuelo sobre el lienzo a comienzos del siglo XIX, con figuras como Pancho Fierro y, el academicista, Daniel Hernández quien tuvo la oportunidad de estudiar en Europa para luego regresar a Lima y fundar la primera escuela de bellas artes del Perú en 1919, reproduciendo conceptos de belleza, estilos, técnicas y cultura que servían para componer y pintar como lo hacían los artistas europeos, y son ellos y sus sucesores los que juzgarán y catalogarán el arte peruano hasta el día de hoy, pasando por alto la corriente indigenista que tuvo su máximo esplendor en la década de 1930 y que poco a poco fue diluyéndose junto a una tendencia en la cual la población se desligaba de su pasado indígena.

Bajo la mirada crítica de la mayor parte de especialistas que hoy dominan los círculos de arte en Lima, la obra de este pintor shipibo sería considerada como una artesanía o, en el mejor de los casos, como arte popular. Las academias no enseñan ni practican este tipo de arte. Los críticos de arte de Lima son quienes legitiman un arte de nivel y deciden qué es lo que debe ser expuesto y donde debe ser puesto; estas instituciones son lugares donde se aprende a pintar y a conducir el pincel; pero no todos los artistas asisten a sus aulas. Si eso pasara, ello construiría un puente para que los artistas shipibos pasen sus obras de una categoría a otra y las miradas se reconfiguren y se produzca algo diferente y particular. En el discurso de Guímer García, nuestro pintor amazónico, menciona que no le gustan las aulas ni el hecho de aprender sentado en un pupitre, tampoco le interesa postular a la academia, porque su fuente de inspiración y enseńanza está en la medida de su purificación espiritual la cual consigue progresivamente cuantas veces participa del ritual de la ayahuasca. A través de este ritual, una característica religiosa propia de su cultura, siente que las plantas, la naturaleza y las visiones le enseñan cómo debe pintar a través de la ingestión de una pócima alucinógena. Según él, las plantas saben cómo comunicarse con los hombres a través de símbolos que el chamán como guía bien le ayuda a traducirlos. Su destreza como pintor radica en la fidelidad interpretativa de los símbolos visuales, de la memoria y los recuerdos que el artista vio durante el ritual, no de lo que podría haber aprendido en una academia o copiando obras.

Los detalles desfiguran la apariencia y nos llevan a un mundo interior interesante. El aparente formato cuadrangular en la obra de Guímer García no es un cuadrado exacto ni está fijado métricamente por el paspartú o el marco de madera de un cuadro, pues él no los necesita, sino algo semejante que es regulado por una línea difusa que se forma por los hilos rotos de una tela que fue cortada, una tela no tensada que puede cambiar su forma en cualquier momento, quitando la simetría del cuadrado. De ese modo, ello solamente refleja una apropiación del discurso artístico que aprendió en el curso de arte del colegio y, en las galerías de Lima cuando llegó por primera vez de Pucallpa. En antropología, a este proceso de aprendizaje se le llama endoculturación y se evidencia en la construcción de la obra de arte; porque pintar sobre lienzos y visitar galerías nunca fue algo que desarrolló la cultura Shipibo en su pasado, solo ahora; por lo menos no de esa manera. En ese 
sentido, es válido indagar hasta dónde llegan las posibilidades del subordinado, en el sentido de qué tiene que hacer para ser reconocido como artista. Así, el pintor que se adapta a las reglas de otra cultura, se permite aceptar y acoplar algunas de las reglas de la academia sin desligarse de su propia identidad, por lo que disfraza sus imágenes, transfigurando lo aprendido y lo observado, haciéndolos ver por los críticos como errores imperdonables, cuando no los son. Una variación sutil toma el formato cuadrado, pero con algunas variaciones casi imperceptibles que hacen que cada lado tenga diferentes medidas, y quiebren la simetría de la forma, ya que la simetría es inconcebible dentro del pensamiento que genera la cultura shipiba.

La pintura "El búho" es una muestra material del arte subordinado que encaja con todo aquello que es producido fuera de la academia; pero la subordinación no como sometimiento, sino como marginación por incomprensión. En ese posicionamiento, la obra de Guímer García es tanto un producto de la influencia europea clásica que se observa en el formato rectangular, como también de la Amazonía; específicamente de lo peruano-shipibo. Ello representa el compromiso irónico del mimetismo que señala Homi Bhabha (2002, p.112). Según Bhabha, por deducción, "es casi lo mismo, pero no exactamente" (Ibíd.) lo mismo, porque ha cambiado sutilmente. En ese sentido, dos figuras copiadas no siempre resultan ser iguales, en una cosmovisión donde sería imposible que existan dos cosas iguales, ello resulta imposible. De ese modo, el formato cuadrado, no es exactamente un cuadrado perfecto, sino con ligeras inclinaciones $y$ desproporciones, las cuales podrían ser vistas desde la academia limeńa como descuidos o falta de talento.

Dentro del formato de la obra se respeta una regla en el sentido que la pintura conforma elementos que reflejan algo parecido a la realidad, pero no exactamente la realidad. Por consiguiente, al seleccionar los elementos figurativos que aparecen en la obra, se observa claramente unos hombres que rodean al búho y soplan sobre él, pero que no se identifican por sí mismos. La imagen debe ser acompañada por un discurso. Por ello, Guímer García avisa que uno de ellos es el chamán "malo" que intenta arruinar el ritual del chamán "bueno", sin tener en cuenta que este último tiene al búho de su parte como su protector, pero ¿cómo podríamos saber cuál es el chamán "bueno" y cuál es el "malo" sin la señalización de Guímer? La explicación aparentemente puede ser clara, pero sin la señalización simplemente no podríamos hacer la identificación adecuada, ya que las características de identificación se pierden y el sujeto discursivo que representa a uno de ellos se confunde con el otro y viceversa; algo propio de la cultura shipiba; creando un problema de autoridad e identidad. Por lo tanto, solo el desplazamiento hacia la lógica de la cultura Shipibo podría revelarnos por qué hay un sincretismo de datos que configuran un estado en el que nada es para diferenciarse del otro. Mientras creer que el hombre vestido de blanco es el "bueno", como seguramente lo haríamos en la lógica occidental, que asocia el color blanco con la pureza, sería como caer en la ingenuidad de una vista rápida o en la mirada que evita la lógica ambigua del pensamiento indígena shipibo.

La lógica Shipibo va más allá, es como lo que advierte Homi Bhabha cuando habla de la ambivalencia (mutuos desplazamientos) y critica mostrar solo y un único punto de vista ordinario que puede representar la crítica de la academia; en esta otra lógica, aplica las múltiples perspectivas de consideración que, quizás tienen una aproximación mucho más real. Así, la identificación de algo o alguien en la pintura va a depender siempre del punto de vista o el 
marco cultural que se maneje; es decir, que puedes pensar que el chamán "bueno" es el de color blanco, lo cual es una posibilidad entre muchas otras, pero si se hace un desplazamiento, podríamos pensar que el chamán "bueno" es el de color verde, color mimetizado con la naturaleza Amazónica. Sin embargo, al preguntarle a Guímer al respecto, dijo que el sujeto era - "el chamán que estaba atrás del búho”. Remirar la pintura y buscar al que está "atrás" parece ser fácil pero hacía falta una indicación o una flecha para señalar al sujeto como exige mi cultura. Una ubicación relativa en un mundo de posibilidades es frecuente en el discurso shipibo, ya que si era el de color "verde" que estaba arriba del búho o el que parece estar detrás de la transparencia del búho, aquel de traje blanco; ambos encajaban dentro del discurso del autor. Al insistirle que señale a Guímer García, nos permitimos tomar un riesgo analítico donde él pueda ser forzado y acomodar su respuesta para satisfacer nuestra visión cultural, y al hacerlo él, queriendo identificar al chamán "bueno", señaló con su dedo al hombre de color "verde".

Podemos resaltar que la obra de arte de Guímer García provoca en el espectador un ejercicio de ambivalencia al tratar de identificar a los personajes, tal como lo trató Homi Bhabha (2002) en el discurso. De igual manera, podemos encontrar este mismo ejercicio en otros elementos de la pintura, como por ejemplo, la ambivalencia de lo bidimensional con lo tridimensional en el edificio de estilo oriental que está en la parte inferior-izquierda de la pintura; donde la perspectiva parece transformarse, volverse plana perdiendo el punto de fuga y, al mismo tiempo manteniendo algo de su esencia. En este momento hay que destacar que las figuras planas parecen mezclarse con las figuras voluminosas en un mismo espacio reforzando la idea. Continuando con la misma lógica, los tapices con diseños geométricos han evolucionado de los kené, son estilizaciones de aquellas antiguas figuras geométricas de la cultura Shipibo (Belaunde, 2009) que parecen imitar los caparazones de las tortugas y, que están en los costados superiores contrastándose con la figura central del búho lleno de plumas y con una mirada amenazadora.

En el modo de pintar, el colonizado o el subordinado artístico, tiene que imitar al colonizador (en su lenguaje), tiene que por ejemplo hablar como él, en otros casos pintar. Así, construye una cultura nueva que desestabiliza la original junto a un repertorio de símbolos particulares. El lenguaje artístico se aprende en las academias, donde Guímer García no ha podido llegar; pero lo que siempre ha hecho desde que llegó a Lima es visitar exposiciones en galerías y tener amigos académicos que le van enseñando cada vez algo más sobre lo que la sociedad limeña y los críticos de arte demandan; en ese actuar está construyendo un arte nuevo, mezclando y transformando dos culturas; la cultura no es estática, pero esta es una de las consecuencias de su variabilidad. En este actuar puede desestabilizar los cánones artísticos de ambas. El profesor Victor Vich de la Pontificia Universidad Católica del Perú señaló una vez en una de sus clases que "toda repetición de un original nunca es idéntica, e implica cambiar y reformular", en el sentido que obliga a pensar de forma diferente. Guímer García reinterpreta figuras occidentales o reevalúa las reglas de composición bajo los dominios de su cultura y pensamiento, buscando semejantes o cambiando formas estilizándolas a su modo.

En la pintura, por decir, el uso de lo figurativo es necesario de algún modo, ya que desea transmitir un mensaje común entre él y sus compradores 
que generalmente son turistas ansiosos de llevarse un recuerdo o algún investigador con conocimientos sobre la cultura Shipibo. Por ejemplo, las figuras muestran las cabezas y los bustos de personas que están pintados de verde, gris o naranja, como si quisieran ser animales o plantas; pieles que no se comparan con el color real de las personas, pero que tampoco desfiguran por completo la percepción que los identifica como hombres, sino que crean una figura ambivalente entre la naturaleza y la humanidad donde no es lo uno ni lo otro, es decir un "between" (traducido del inglés: "entre"). Estar en el medio, para señalar el equilibrio triangular que es representado por la frente del búho. En consecuencia, hay una amenaza a la imitación, al tratar de llegar a ser como el otro, porque desestabiliza a este otro. Adicionalmente, la amenaza que se expresa en el cuerpo erguido y la mirada fiera del búho dirigida hacia el espectador, subordinan a los hombres presentes que están conscientes del espectador, sino que además representan la naturaleza: el animal salvaje. Los hombres en la representación son semejantes pero no iguales: cambian de color, de acciones y hasta de vestimenta, pero mantienen rasgos particulares como los labios carnosos, una nariz aguileńa, cuello largo, cabello corto, cejas voluminosas, ojos y pómulos grandes.

Aunque, un mejor uso del pincel podría haber alcanzado la exigencia de un ojo occidental que lo evaluaría; algo que, podría perfeccionarse en la academia. Sin embargo, no parece ser el fin del cuadro, ni la intención del autor, porque la amenaza es un componente y una intención premeditada detrás de la pintura; la amenaza debe estar presente y camuflada para la crítica de la academia. Lo cual "proyecta una amenaza inmanente tanto sobre el saber "normalizado" como sobre los poderes disciplinados" (Crehan,
2002, p. 112). Es una amenaza latente que debe ser silenciada, con la voz que encasilla y clasifica a la pintura como un arte popular, evitando que vaya más allá. Podría ser que el mimetismo es un camuflaje, que esconde el preguntarnos ¿Quién está detrás del búho realmente? Recordando que, dentro de la cultura Shipibo se consideraba que antes los Shipibo eran animales, y no había distinción entre lo que occidente distingue como lo animal y lo humano, sino que antes todos eran animales (Soria Casaverde, 2004). Por consiguiente, no será que el búho es un humano disfrazado desde la perspectiva Shipibo, que solo es reconocible a través de su mirada, como si fueran las ventanas de su interior, para encontrar al otro humano, que en la misma esencia podría ser la naturaleza que fue conquistada y colonizada por el hombre.

La pintura de Guímer García se ha alineado a un lenguaje artístico conservando ciertas reglas del arte europeo, como el uso del lienzo, los pinceles y algunas figuras de seres simbólicos que aparecen reinterpretados desde la cultura del autor. En otras palabras, se cambian sutilmente los colores de la representación original, o las pequeñas variantes que distinguen cada forma una de otra. La obra de arte representa el mimetismo del indígena subordinado a una academia de arte occidental, pero donde su posición no queda tan clara, porque al mismo tiempo está creando formas nuevas de pintar, generando un nuevo estilo, el cual todavía mantiene ciertos rasgos figurativos culturales como los Kené (Belaunde, 2012).

Los cánones europeos están dentro del aspecto compositivo de una obra occidental, sin embargo, los cánones estéticos shipibo están compuestos por las líneas de los kené, ambos cánones con lógicas, reglas y medidas distintas. 
Un intento de armonizar ambas perspectivas, es el resultado artístico de Guímer García en la obra "El búho", quien parte de un cuadrado simple que no es más que la forma básica de la estructura de un rectángulo, para conservar o satisfacer la armonía de ambas culturas. Por lo tanto, si no tomamos en cuenta o consideramos la lógica de la construcción de los motivos kené, la pintura queda en la escala compositiva más simple de occidente, algo quizá sin sentido ni armonía. Sobre esto, una especialista, señaló que todavía la obra es arte naif, sin embargo, ¿Qué pasa si vemos desde otro punto de vista, desde el punto de vista del subordinado, entendiendo su cultura? Encontraríamos, en ese caso, nuevamente la ambivalencia entre el uso del cuadrado (estático) y el rectángulo (dinámico), señalando que ambos pueden convivir en un mismo espacio. Es decir, que dentro del formato semicuadrado con una composición simétrica que divide a la pintura en cuatro áreas, identificaremos claramente pequeñas áreas rectangulares que niegan la simetría (figura 01), dándole dinamismo a lo que en un principio no parece hacerlo. En ese sentido, encontraremos en la composición simétrica del cuadrado, elementos de asimetría. Por lo tanto, la pintura contiene contradicciones en sí misma, pero al mismo tiempo, trata de estabilizarse. Recordemos que el discurso artístico shipibo no es dicotómico, deconstruye las fronteras, donde todas las figuras poseen algo de los otros, es decir que hay símbolos interconectados y pensados dentro de la composición, los cuales jalan la forma de mirar del espectador. Por eso, la pintura de Guímer García representa el discurso del que señala Bhabha, pero en este caso adaptado a lo visual que se percibe en la pintura en donde la sobreposición, la yuxtaposición y el entrecruzamiento de figuras, hacen que cada figura posea algo de la otra y viceversa.

\section{Repensar y valorar la obra de arte}

La obra de arte "El búho" se convierte en el objeto que va a sustituir la discriminación étnica. El pensamiento shipibo se hace evidente bajo un análisis más profundo de las obras de arte desde un discurso que ha dominado a algunos especialistas del Perú, quienes siguiendo las reglas europeas compositivas, no siempre encuentran las reglas compositivas Shipibo mezcladas con las de occidente. La pintura tiene que imitar la pintura del colonizador lo más que se pueda; no desprendiéndose de su cultura, pues provocaría cambios irregulares y sin sentidos para la construcción de una identidad. Leer cuadros ahora es más difícil, por ejemplo aquella redistribución ambigua de rectángulos que configuran la composición interna de la pintura, sin un entendimiento claro de la cultura shipiba no podría tener sentido desde una mirada académica o europea. Guímer García imita algunos detalles de obras contemporáneas, pero su repetición nunca es idéntica, y siempre ha implicado cambiarlo y reformularlo, pasando por el filtro de su propio pensamiento cultural y de su concepto étnico relacionado a la naturaleza. Todo actuar nuevo, desestabiliza las reglas originales tanto de lo europeo como de lo shipibo. Este proceso fue llamado por H. Bhabha: "Mímesis" (2002: 112), y encaja perfectamente dentro de las relaciones sociales de construcción de obras de arte de Guímer García o en general de los artistas Amazónicos. 
Es interesante notar que en la estructura compuesta por los elementos figurativos de la pintura está detrás de una representación. La pintura muestra elementos relacionados con la selva, para poder ser reconocida como una pintura amazónica, pero como no se ha construido en base a los cánones de belleza occidentales que se enseñan en la academias, la pintura no reproduce el poder del canon estético de occidente y, por lo contrario, va en contra de este poder, desestabilizándolo, esto se representa en la marginación y en la desvalorización.

Adicionalmente, el discurso de occidente producido en las academias o escuelas de arte, narra un proceso lineal que pasa de la artesanía al arte popular y luego al arte contemporáneo o propiamente dicho. Las obras de arte de Guímer Guímer, incluso por las que han tenido que pasar otros pintores Amazónicos como Rember Yahuarcani (Borea, 2010), son puestas en esas narrativas lineales del progreso artístico. Lo que hace que por el momento, su obra se la ubique dentro de lo que catalogamos como "arte popular", no obstante, su no alienación a las reglas de juego imperantes se convierte en la excusa sutil y material para categorizar objetos; pero, al mismo tiempo, se disfraza la discriminación a una población étnica de la cual sus pensamientos y su cultura se desconocen, $y$ pueden ser estos tan complejos como cualquier otro tipo de pensamiento que genera cultura y arte.

La forma de representación de Guímer García difiere de lo acostumbrado en las academias de arte; ya que este arte es situado. Este y otros artistas contemporáneos que migraron a la Capital vivieron la mayor parte de su vida en la Amazonía, cada uno con una cultura que todavía se mantiene ahora que viven en Lima; una forma de pensar y de actuar típica del lugar, que permite que vean el mundo desde lo que ellos denominan "lo shipibo". Si se tiene en cuenta que "representar es hacer presente lo ausente" (Debray, 1998: 34), y lo ausente es el contexto amazónico. Los recuerdos de los artistas son reformulados en las visiones que aparecen cuando participan en el ritual de la ayahuasca, porque guían las formas y colores de las figuras de los animales, plantas, mitos, seres mitológicos y humanos de la pintura. Así, crean sus propios repertorios de elementos simbólicos que configurarán cada cuadro. El orden y el dibujo de estos elementos corresponderán más a la forma en que piensan, en cómo ven a los animales y a las plantas; como seres dominantes dentro del espacio del lienzo, que evidencian que la naturaleza los ha colonizado.

En el análisis de la obra "El búho" de Guimer García, los conceptos de mímensis y ambivalencia adicionan información para dar paso a una reformulación interpretativa que puede cambiar los textos sobre la selección de obras en los museos de arte contemporáneo, especialmente en Lima. Todavía, esta pintura es ofrecida por las calles de la ciudad de Lima a costos bajísimos, a la espera de ser comprada por algún turista o extranjero que las valore más, inclusive pagando más que un local, para llevarse algo que quizá nunca más lo volvamos a ver.

La manera de producción de la obra de Cantagallo es igual de compleja o similar a cualquiera producida por los artistas académicos, ya que implica un aprendizaje cultural (endoculturación). Solo que el desconocimiento 
de la cultura Shipibo y amazónica en general hace desvalorizar la obra de arte que podría ser en caso contrario mejor apreciada. Los artistas de Cantagallo no producen un arte típico ni exótico, sino han creado un estilo nuevo y evolucionado que hay que estudiarlo, ya que han incluido algunos conocimientos del arte occidental, desde el formato cuadrado del lienzo hasta el uso de acrílicos para pintar. En ese sentido, podemos señalar que los pensamientos de Guímer García al pintar la obra "El búho" o de los otros pintores, no corresponden a una cultura Shipibo diferenciada de la cultura occidental, sino al de otro modo, que concuerda con el punto de vista de Homi Bhabha, que aplicado señala que el pensamiento del autor es más "ambivalente", es decir que no es ni shipibo ni occidental, sino está entre los dos y que poco a poco serán uno.

Finalmente, este enfoque analítico concuerda con el estilo ambiguo del pensamiento en la Amazonía (Descola, 1998; Gonçalves, 2007), en donde todo parece mimetizarse. Cuando le preguntamos a Guímer García cómo podría entender mejor su arte y cultura, él respondió: “¡Shipibízate!”. Seguramente para situarnos en su lugar, en su cultura, en sus cánones, en su orden, en su perspectiva para poder entender la complejidad de su obra de arte, y ver no una simple tela llena de pinturas, sino una ventana al mundo amazónico, a sus reglas y cánones estéticos. Ello permitiría una revaloración al arte shipibo, en sentido general, y a la inclusión de artistas como Guímer García dentro de un reconocimiento como tales en la Academia.

\section{Bibliografía}

Belaunde, L. E., (2012). Diseños materiales $e$ inmateriales: La patrimonialización del kené shipibo-konibo y de la ayahuasca en el Perú. Mundo Amazónico, 3, pp. 123-146.

Belaunde, L. E., (2009). Kené: arte ciencia y tradición en diseño. Lima: Instituto Nacional de Cultura.

Bhabha, H., (2002). El lugar de la cultura. Buenos Aires: Manantial.

Borea, G., (2010). "Personal cartographies of a Huitoto mythology: Rember Yahuarcani and the enlarging of the Perubian contemporary art scene". En Rev. De antropología social dos Alunos do PPGAS-UFSCar, v.2, n.2, jul-dic. Pp.67-87.

Crehan, K., (2004). Gramsci, cultura y antropología. Barcelona: Bellaterra.

Debray, R., (1998). Vida y muerte de la imagen. Historia de la mirada en occidente. Barcelona: Paidós.

Descola, P., (1998). Las cosmologías de los indios de la Amazonía. Zainak, 17, 1998, pp. 219-227.

Gonçalves, M. A, (2007). Personalidad y procesos de subjetivación en una ontología amazónica. Amazonía Peruana, Tomo XV, 30, diciembre, pp. 159-184.

Soria Casaverde, M. B., (2004). Introducción al Mundo Semiótico de los diseños Shipibo-Conibo. Lima: UNMSM y Seminario de Historia Rural Andina. 